\title{
Promoting healthy computer use among middle school students: a pilot school-based health promotion program
}

\author{
Marina Ciccarelli ${ }^{* a}$, Linda Portsmouth ${ }^{\mathrm{b}}$, Courtenay Harris ${ }^{\mathrm{a}}$ and Karen Jacobs ${ }^{\mathrm{c}}$ \\ ${ }^{a}$ Curtin Health Innovation Research Institute, School of Occupational Therapy and Social Work, Curtin \\ University, GPO Box U1987, Perth, WA 6845, Australia. \\ ${ }^{\mathrm{b}}$ Curtin Health Innovation Research Institute, School of Health Promotion, Curtin University, Perth, Australia \\ ${ }^{\mathrm{c}}$ Sargent College of Rehabilitation Sciences, Boston University, Boston, MA. USA
}

\begin{abstract}
Background: Introduction of notebook computers in many schools has become integral to learning. This has increased students' screen-based exposure and the potential risks to physical and visual health. Unhealthy computing behaviours include frequent and long durations of exposure; awkward postures due to inappropriate furniture and workstation layout, and ignoring computer-related discomfort. Objective: Describe the framework for a planned school-based health promotion program to encourage healthy computing behaviours among middle school students. Methods: This planned program uses a community-based participatory research approach. Students in Year 7 in 2011 at a co-educational middle school, their parents, and teachers have been recruited. Baseline data was collected on students' knowledge of computer ergonomics, current notebook exposure, and attitudes towards healthy computing behaviours; and teachers' and self-perceived competence to promote healthy notebook use among students, and what education they wanted. The health promotion program is being developed by an inter-professional team in collaboration with students, teachers and parents to embed concepts of ergonomics education in relevant school activities and school culture. End of year changes in reported and observed student computing behaviours will be used to determine the effectiveness of the program. Significance: Building a body of evidence regarding physical health benefits to students from this school-based ergonomics program can guide policy development on the healthy use of computers within children's educational environments.
\end{abstract}

Keywords: ergonomics, schools, notebooks, community-based research

\section{Introduction}

Ninety-two percent of Australian children aged 514 years use information and communication technologies (ICT) including computers, with increased use correlated with higher age [1]. Eighty-seven percent of boys and $80 \%$ of girls regularly participate in electronic screen-based activities [3]. A recent Australian government initiative to ensure that young Australians are well equipped for a more technologically advanced future has seen an estimated $\$ 1$ billion allocated to provide more than 290,000 computers to over 2,800 schools in Australia [9]. Government and non-government schools are increasingly providing curricula and learning environments in which individual notebook computers are integral to students' daily in-class and at-home learning activities; and are commonly referred to as 1:1 Notebook Programs [13].

These 1:1 Notebook Programs have resulted in a considerable increase in students' exposure to screenbased media. With the learning benefits associated with these new technologies comes the potential risk to children's physical and visual health, especially in critical stages of their physical development.

Discomfort associated with high computer use among adults is well documented [11], with increasing concerns about the physical and visual health of children using ICT [18]. Ongoing discomfort in childhood is a risk factor for the development of chronic musculoskeletal disorders in adulthood, which can disrupt participation in important self-care, work and leisure activities. Prior research has found

*Corresponding author. E-mail: M.Ciccarelli@curtin.edu.au 
significant associations between discomfort among children and hours spent using ICT [12,17,18], and a study of Western Australian children aged 10-17 years found that $60 \%$ of children reported discomfort when using their laptops [14]. In a survey of 218 primary school teachers, $19 \%$ of teachers reported their students complained of eye discomfort while computing [25]. Likewise, another study found that $38 \%$ of 212 primary and high school children reported computer-related eyestrain [6], with higher use related to greater reported discomfort. Furthermore, when children experience discomfort during computer use, they are likely to work through the discomfort, rather than seek solutions [21]. This may be because children fear losing their access to ICT if they report discomfort to parents or teachers.

Discomfort is likely associated with children's unhealthy computing behaviours including frequent and long durations of computer use [8], adopting awkward postures because of inappropriate seating and furniture and workstation layout, inadequate forearm support during keyboard and mouse use [8], and ignoring discomfort experienced when computing [21]. School children often use computers at school and home for long durations and in non-variable postures, using workstations that are a poor fit to their needs $[7$, 15], increasing the risk of muscle and visual discomfort and developing chronic health problems. The presence of these unhealthy behaviours may increase children's risk of physical and visual discomfort and long term health.

A 2010 study [24] of 537 Year 5 Western Australian students identified that a majority of participants were concerned that computer use could affect their physical health; and believed they would adopt healthy computing practices if shown how to, and encouraged to do so by their parents, teachers and peers. However, they were unsure whether their parents, peers or teachers were concerned about them using computers in a healthy way, suggesting a lack of communication and awareness about this important childhood health issue.

Many schools integrating ICT into their curricula are proactive in promoting the psychological and mental health of students using computers, especially with respect to cyber-bullying and avoiding online predators [23]; through school policy; providing workshops for students and teachers, and giving information to parents through newsletters. However, at an international and local level, there appears to be less attention given by schools to promoting students' physical and visual health when using ICT, and interventions are often at a micro-ergonomics level [20].
Prior ergonomics interventions for school children have been limited because outcome measures to determine effectiveness were not reported, or aimed to increase student knowledge about ergonomics with the assumption this would change unhealthy behaviours. Shinn and colleagues highlighted the fact that external factors, including the school environment, restricted changes; especially changes in workstation design and associated postures [22].

\section{The need for a school-based ergonomics education program}

The research team was approached by the Assistant Principal and Head of Middle School at a nongovernment K-12 school in Perth, Western Australia, seeking assistance with the implementation of a 1:1 notebook program for Year 7 students in 2011. Senior management at the school was concerned about possible negative physical health effects the introduction is these digital technology may have on the students.

Preliminary discussions with the school identified the potential to develop and implement a schoolbased health promotion program that adopted a macro-ergonomics approach. A community-based participatory research design was selected for this health promotion project. Community-based participatory research is a collaborative approach to research that involves community members, organizational representatives, and researchers in all aspects of the research process. Each partner contributes unique skills and knowledge to enhance understanding of the health issue, the cultural dynamics of the community, and integrate the knowledge gained with action to improve the health and well-being of community members [16]. It is therefore well-suited to facilitate a cultural shift within schools regarding the relevance of macro-ergonomics in educational environments.

Facilitating change in the health behaviour of any community, including Year 7 middle school students in a 1:1 notebook program, requires a macroergonomics approach that includes attention to epidemiological risk factors; as well as the attitudes of the entire community (teachers, students and their parents) towards the health-enhancing behaviours; and environmental factors, such as the physical learning environment (furniture, seating, lighting) and organisational environment (culture of the school). The likelihood that members of the school community (students, teachers and parents) will promote 
and/or adopt health-enhancing behaviours is based on a combination of knowledge, attitudes and skills [10] and opportunities for change afforded within the culture of the school.

\section{Developing the health promotion framework}

\subsection{Phase 1: Understanding the organisational culture}

The goal of introducing a change in how students and teachers safely utilized digital technologies including notebooks was initiated by senior school management with the support of the Year 7 teachers responsible for this cohort of students. This was to ensure the school met its duty of care for maintaining students' health and well-being as well as from a moral perspective to ensure the application of technologies was done in a responsible manner. Obtaining commitment and support from the highest levels of management within an organisation is essential for bringing about successful change. This commitment also fits with a participatory research design approach wherein the community partner identifies the need and drives the intervention.

This health promotion intervention with the Year 7 students is viewed by school management as a pilot and exemplar for bringing about similar changes in school culture and behaviours regarding educational ergonomics across other year groups in subsequent years. School management supports building capacity among teacher staff, to increase their knowledge, skills and confidence to facilitate healthy use of technologies among students.

As such, the school management has provided a commitment to provide resources for achieving this goal, such as the purchase of appropriate furniture for classrooms. This includes alternative seating arrangements to traditional desks and chairs, for example, couches, bean bags, and height adjustable childsized furniture to provide students with flexibility and variation in the postures they use. Purchase of furniture and equipment is being done in collaboration with ergonomics experts so as to ensure appropriate furniture is selected to meet the needs of the students. Options for students to work collaboratively in small groups or individually in the classroom environments are also offered. Moving away from the traditional concept of students remaining seated in one place during a lesson, students will have the opportunity to change their work postures and seating as required in response to any discomfort experienced, thereby providing students with greater responsibility and opportunity for self-management of their physical and visual health.

\subsection{Phase 2: Identifying knowledge of, and attitudes towards healthy computing, among school community members}

The baseline knowledge of and attitudes towards computer ergonomics among the Year 7 students were assessed using a validated questionnaire designed for use with children that has acceptable testretest reliability [19]. The measure included eight multiple choice knowledge items related to posture during notebook use. Students' attitudes towards healthy computing were assessed using the same instrument. Domains included perceived susceptibility to negative health associated with notebook use, perceived severity of negative health outcomes associated with notebook use, self-efficacy, subjective norms and cognitive, affective and behavioral components of attitude.

Year 7 teachers were surveyed anonymously about their self-perceived competence to promote healthy use of notebooks among their students. Teachers responded that notebooks and other ICT were integral to the students' learning experiences in the classroom and at home. The teachers also responded that they were concerned about their students' physical health; however, none of the teachers reported being confident in their knowledge and skills to minimise physical health risks among students using these digital technologies. None of the teachers reported receiving any formal training in applying ergonomics principles to the healthy use of computers and other technologies.

\subsection{Phase 3: Identifying how to apply the intervention in the context of the community partner}

Two focus groups (comprising nine and 11 students respectively) were held with key informants among the students who provided consent to participate in this study, as representatives of all Year 7 students at the school. Participants were provided with a general summary of the grouped results of the questionnaires the students had previously completed. It was reported to the focus that many students knew some aspects of healthy notebook computing, but that none of the students knew all aspects. It was also reported that over half of the students who completed 
the questionnaire reported discomfort associated with notebook use; and that the majority of students responded in the questionnaire that they would like to know more about healthy notebook use and would do so, if shown how by their teachers, parents and peers.

Students in both focus groups were asked to identify strategies promoting healthy notebook use and how they should be introduced into the school community to positively change student and teacher behaviours. Focus group participants provided suggestions around the types of information that would be important to include, the various forms of media and technologies available to disseminate the information, where the information would be placed to maximize exposure to members of the school community; and how often the information presented should be updated to remain novel and interesting. All focus group participants believed students should contribute to the development of the media that would be used, which is consistent with the community-based participatory research model that "facilitates collaborative partnerships in all phases of the research" (p.178) [16] .

At the time of preparing this manuscript, focus groups with the Year 7 teachers at the school were planned to discuss which of the various forms of ergonomics education media the students had identified were suitable to be incorporated into the Year 7 curricula activities. For example, the development of posters with messages about healthy notebook use could be the focus of art classes; still and motion picture 'advertisements' about healthy notebook use may be appropriate for students to develop in their media studies class; writing blogs on the school's internal newsletter may be a suitable forum for inclusion in English class; and researching the content to include in these media messages could be appropriate for inclusion in Health classes.

Further to this, agreement needs to be reached with the teachers about how to develop and implement a more flexible approach to the working postures of the Year 7 students using notebooks. The School administration supports providing a range of alternative seating arrangements for students including couches, benches, height adjustable ergonomic chairs and bean bags. As variation of posture is a key ergonomic recommendation for minimizing discomfort among children using ICT [8], the classroom culture and teachers' expectations of how students work will need to adapt to accommodate this recommendation. Providing opportunity for students to adjust or change their seating and working postures is a shift away from traditional classroom structures were students remain seated in one place for the duration of the class. Successful integration of a model where students take responsibility for adjusting their postures to either prevent or respond to discomfort, will require negotiation between students and the teachers to ensure it is managed to limit distraction to students and disruption to the learning activities.

\subsection{Phase 3: Involving all community members}

Implementing the healthy notebook health promotion program will commence with the Year 7 students. However, a shift in the school's culture (among all students and teaching staff) is necessary to ensure that as these students progress in higher grades each year, the healthy ways of working they develop will be encouraged and enabled by teachers. Therefore the healthy notebook 'messages' that the students develop in conjunction with the research team and their teachers will be disseminated to students and teachers in other year groups at the School.

Prior research identified that many children do not discuss healthy ways of using technology with their teachers or parents [24], despite both being influential to young people's behaviours. Parents of the Year 7 students are invited to participate in a workshop facilitated by members of the research team and a ParentTeen coach to learn more about the health issues related to notebook use among young people, and how they can reinforce the healthy notebook messages in the home environment. Parents will be asked to complete a brief survey prior to the workshop to measure their perceived competence to promote healthy use of technologies among their children in the home environment. Information about the ergonomics related to notebook use and strategies to facilitate healthy ways of working in the home will be provided by the research team. Strategies on how to communicate healthy ways of working to their pre-teen children will be facilitated by the Parent-teen coach who has expertise in communication between parents and their children. Incorporating all key stakeholders in the school community (senior administrators, teachers, students and parents) in the development and implementation of the healthy notebook promotion program, is likely to empower members of the community to bring about the change in culture and notebook use behaviours that the school community's members have identified as a concern. 


\subsection{Phase 3: Providing opportunity for feedback}

As the health promotion program is implemented in the school community by the Year 7 students and their teachers; and changes are introduced to the physical classroom environment (e.g. seating, workstations, lighting) by school administrators, the research team will facilitate opportunities for discussion among and between members of the community to determine any modifications or additional resources that they have identified as important for the success of the program.

\subsection{Phase 4: Evaluating program outcomes}

The anticipated outcomes of this community-based health promotion program are a positive change in the knowledge, attitudes, healthy behaviours and discomfort experienced among the Year 7 students when using notebook computers, compared to their baseline measures. Teachers and parents will also be reassessed using baseline measures of their competence to promote healthy use of technologies among the students.

More importantly, however, will be the evaluation of how the school community members perceive the healthy notebook program has brought about change to the culture of the school regarding notebook computer use. Specifically, how physical changes to the classroom environments were introduce and managed; how successfully were the healthy notebook use/ergonomics messages developed and disseminated among the Year 7 group and wider school community; how well were teachers able to adapt their classroom structure to allow students to selfmanage their working postures when using notebooks; and whether or not Year 7 students provided peer support to encourage healthy notebook behaviours among their fellow students.

\subsection{Phase 4: Building capacity and sustainability}

As these Year 7 students progress through middle school and high school, it will be important that they continue to be supported to use their notebooks (or other portable digital technologies as they evolve) in healthy ways to minimize discomfort and risk of musculoskeletal complaints.

Building capacity to promote healthy use of notebooks among teachers in other year groups may be achieved through professional development sessions or peer support from the current Year 7 teachers. The tertiary programs for teacher education in Western Australia currently do not include any ergonomics education in the course curricula. The need for ergonomics to be included in the education of pre-service teachers has been identified as a global concern [20], and is the focus of future research by the authors.

\section{Conclusion}

This paper has outlined the framework for implementing a planned health promotion program among Year 7 students who are involved in a 1:1 notebook computer program at school. The planned program utilizes community-based participatory research combined with a macro-ergonomics approach that considers the physical school environment, knowledge, attitudes and behaviours of school community members to promote healthy notebook use among students. Findings from the study will be published after the program is completed and evaluated.

\section{References}

[1] Australian Bureau of Statistics. 4901.0 - Children's participation in cultural and leisure activities, 2006, Canberra.

[2] Australian Bureau of Statistics. 8126.0 - Information and communication technology, Australia 2006-07, 2006, Canberra.

[3] Australian Bureau of Statistics. 4901.0 - Children's participation in cultural and leisure activities, 2009, Canberra.

[4] C. Bennet, Computers in the elementary school classroom, Work 18 (2002), 281-285.

[5] C. Bennet, M. Alexandre and K. Jacobs, Developing hands-on ergonomics lessons for youth, 2006, http://www.iea.cc/ergonomics4children/pdfs/art0236.pdf

[6] A. Burke and E. Peper, Cumulative trauma disorder risk for children using computer products: results of a pilot investigation with a student convenience sample, Public Health Reports, 117 (2002), 350-357.

[7] M. Ciccarelli, L. Straker, S. Mathiassen and C. Pollock, ITKids: does computer use reduce postural variation in children? Proceedings of the International Ergonomics Association Conference, 2006, Maastrich, Netherlands.

[8] M. Ciccarelli, L. Straker, S. Mathiassen and C. Pollock, ITKids Part II: Variation of postures and muscle activity in children using different information and communication technologies, Work 38 (2011), 413-427.

[9] Department of Education and Workplace Relations, The Digital Education Revolution- putting computers in front of secondary school students, 2009, http://www.deewr.gov.au

[10] G. Egger, R. Spark and R. Donovan, Health promotion strategies and methods (2nd ed.), McGraw-Hill, North Ryde, N.S.W 2005

[11]F. Gerr, M. Marcus and C. Monteilh, Epidemiology of musculoskeletal disorders among computer users: lesson learned from the role of posture and keyboard use, Journal of Electromyography and Kinesiology 14 (2004), 25-31. 
[12]R.M. Gillespie, M. Nordin, M. Halpern, K. Koenig, N. Warren, and M. Kim, CAKE (Computers and Kids' Ergonomics): The musculoskeletal impact of computer and electronic game use on children and adolescents, Dissertation, New York University, 2006.

[13] Going 1:1 laptop program. Tech Talk Tuesday: Online Webinars for global educators to share and converse, http://techtalktuesdays.global2.vic.edu.au/tag/11-laptopprograms/

[14]C. Harris and L. Straker, Survey of physical ergonomics issues associated with school children's use of laptop computers, International Journal of Industrial Ergonomics 26 (2000), 337346.

[15]C. Harris, L. Straker, C. Pollock, and S. Trinidad, Musculoskeletal outcomes in children using information technologythe need for a specific etiological model, International Journal of Industrial Ergonomics 35 (2005), 131-138.

[16]B.A. Israel, A. Schulz, E. Parker and A.B. Becker, (1998). Review of community-based research: assessing partnership approaches to improve public health, Annual Review of Public Health 19 (1998), 173-202.

[17]K. Jacobs and N. Baker, The association between children's computer use and musculoskeletal discomfort, Work 18, (2002), 221-226.

[18]K. Jacobs, S. Hudak and J. McGiffert, Computer- related posture and musculoskeletal discomfort in middle school students, Work 32 (2009), 275-283.

[19] M. Jones, The development of a valid and reliable measure to assess the knowledge of and beliefs about healthy laptop computer use among secondary school students, Honours dissertation, Curtin University, 2009.

[20]S. Legg and K. Jacobs, Ergonomics for schools, Work 31 (2008), 489-493.

[21]B. Royster, A healthy approach to classroom computers: Preventing a generation of students from developing repetitive strain injuries, North Carolina Law Review 80 (2002), 275314.

[22] J. Shinn, K.-A. Romaine, T. Casimano and K. Jacobs, The effectiveness of ergonomic intervention in the classroom Work 18 (2002), 67-73.

[23]K. Subrahmanyam and P. Greenfield, Online communication and adolescent relationships, The Future of Children 18 (2008), 119-146.

[24]T. Tran, Factors influencing school children's unhealthy computing behaviours. Honours dissertation, Curtin University, 2010.

[25]I. Williams, T. Cook and T. Zigler, Computer Ergonomics for teachers and students. Paper presented at the 14th Triennial Congress of the International Ergonomics Association and 44th Annual Meeting of the Human Factors and Ergonomics Society, 2000, Santa Monica, CA. 